\title{
Congener specific determination of polychlorinated biphenyls (PCBs) in human milk
}

\begin{abstract}
Eighteen congeners Polychlorinated biphenyls (PCBs) congeners were analyzed in 38 human milk samples collected from different ages living in Eastern and Central provinces in Saudi Arabia. The PCB profile was dominated by higher chlorinated congeners. Non-ortho PCB congeners which have the highest Toxic Equivalency Factor (TEF) values were detected in all of individual samples. PCB-81 and PCB-153, the most dominating PCB congeners, which might therefore be used as an indicator for sum PCBs. Toxic Equivalents Factor (TEF) for mono-ortho substituted PCB congeners indicated higher exposure to toxic PCBs in Eastern province rather the Central due to main petroleum industry activities, but estimated daily intakes for both provinces indicate that infants consuFming mother's milk are not at risk of adverse effects caused by PCBs. Our study builds the first database in Saudi Arabia research of human milk samples.
\end{abstract}

Keywords: saudi Arabia, human milk, PCBs, EDI
Volume 6 Issue 4 - 2017

\author{
Mohamed H EL-Saeid, ${ }^{1,2}$ John B Sapp, ${ }^{2}$ Ashraf \\ $S$ Hassanin ${ }^{3}$ \\ 'College of Food and Agricultural Sciences, King Saud University, \\ Saudi Arabia \\ ${ }^{2}$ Chemistry Department, Texas Southern University, USA \\ ${ }^{3}$ Central Laboratory of Residue Analysis of Pesticides and Heavy \\ Metals in Food, Agriculture Research Center, Egypt
}

Correspondence: Mohamed H EL-Saeid, College of Food and Agricultural Sciences, King Saud University, Riyadh I I45 I, Kingdom of Saudi Arabia, Email elsaeidm@ksu.edu.sa

Received: October 10, 2016 | Published: February 27, 2017

\section{Introduction}

Many international efforts have been spent to eliminate and/or reduce the emissions and discharges of a wide range of pollutants that have persisted in the environment as well as living organisms. ${ }^{1}$ These pollutants are known as a persistent organic pollutants (POPs). Contamination from POPs is a pervasive global problem that urgently demands a global solution. ${ }^{2}$ These chemicals include organochlorine (OC) pesticides, such as DDT, endrin, dieldrin, aldrin, chlordane, toxaphene, heptachlor, hexachlorobenzene, mirex. POPs also include industrial chemicals and byproducts, such as polychlorinated biphenyls (PCBs), polychlorinated dibenzo- $p$-dioxins (PCDDs) and dibenzofuranes (PCDFs).

PCBs are a mixture of synthetic organic compounds which do not exist naturally in the environment. These compounds are composed of chlorinated biphenyl rings. Theoretically, 209 isomers could be produced, which are different in the degree of chlorination and chlorinated positions. PCBs are hydrophobic, lipophilic, colorless to light yellow, nonflammable, and oily liquids or crystalline solids without smell or taste. Their viscosity, hydrophobility and stability increase as the number of chlorines increases. ${ }^{3}$ The half-lives of the congeners range from 1day to 70years. Because of their electrical insulating properties, mixtures of PCBs had been broadly used as coolants and lubricants in electrical transformers, capacitors and hydraulic equipment, and also used as plasticizers in plastic and rubber products. The massive production of PCBs in industrial and commercial applications started in 1929. Following the widespread usage, their hazardous effects on ecosystems and humans were gradually observed, leading to the ban on manufacture in the U.S. in 1977 and the removal of the PCB-containing equipment by 2025 under the Stockholm Convention on Persistent Organic Pollutants.

These chemicals tend to degrade slowly in the environment due to their resistance to biodegradation. Thus, they are prone to biomagnification, in which they exert their toxic effects at different trophic levels, and may also have long half-lives in humans. Certain adverse health and reproductive outcomes have been attributed to these chemicals, including certain cancers, ${ }^{4,5}$ birth defects, ${ }^{6,7}$ dysfunctional immune and reproductive systems, ${ }^{8}$ greater susceptibility to disease and even diminished intelligence. ${ }^{9}$ Human milk is the natural and superior food for infants and contains the optimal composition to meet their nutritional needs in early life. Human milk also provides immunological, psychological and economic advantages. Yet, human milk - while still the best food for infants - has been unintentionally compromised by unwelcome chemicals from our environment. The presence of these chemicals is the result of eating, drinking, and living in a technologically advanced world. However, human milk is a unique biological matrix for monitoring certain environmental contaminants because it can provide exposure information about both the mother and breastfed infant through a non-invasive method of collection. Consequently, human milk monitoring can yield information about the types and quantities of POPs in the environment and our bodies. Milk monitoring can also provide a better understanding of our exposure to harmful environmental chemicals, which may help us to better manage such chemicals by eliminating or reducing emissions or limiting their presence in the food supply and environment.

Breast milk monitoring programs have been performed in several countries for investigating geographical and temporal trends in human exposure to POPs. In 2002, the Kingdom of Saudi Arabia signed the Stockholm Convention, and it was ratified in 2012. The present study will be the first comprehensive profile investigating the level of the current PCBs background levels in breast milk of a selected Saudi lactating mother's population. The aim of this study was to determine individual PCB- congeners, especially the non-ortho substituted PCBs, in Saudi human milk for toxicological assessment. Several non- and mono-ortho PCBs are approximate isostereomers of 2,3,7,8-tetrachlorodibenzo- $p$-dioxin (TCDD), the most toxic dioxin congener, and induce similar toxic effects. The levels of the non- and mono-ortho PCBs are given as toxic equivalencts (TEQs) in relation to TCDD also included in this study.

\section{Materials and methods}

\section{Standards and reagents}

PCBs calibration and injection standards were of $99.9 \%$ purity and 
purchased from AccuStandard, New Haven, CT, USA as individual or mixture standards at a concentration of $1000-2000 \mu \mathrm{g} / \mathrm{mL}$. All internal standards are 13C12-labelled for 4 PCBs congeners $(28,81,101,118$, 156, and 189) were used. All solvents (acetone, hexane, methanol, cyclohexane, diethyl ether, ethyl acetate, dichloromethane and acetonitrile) used for the extraction and analysis procedures of PCBs were residue-analysis grade $99.9 \%$ purity and obtained from Fisher Scientific (Fair Lawn, NJ, USA), Diatomaceous earth (Hidromatix).

\section{Questionnaires handling}

Sapling questionnaires were prepared according to the WHO/ UNEP-Coordinated Survey Questionnaire for Human Milk donors for Persistent Organic Pollutants analysis [10] (UNEP-coordinated Survey of Mothers' Milk for Persistent Organic Pollutants, Annexes Guidelines for Organization, Sampling and Analysis, Chemicals Branch United Nations Environment Program (UNEP) July 2012, was filled full in all respondents until the end of the study. Questionnaires of donors retention of all records conform to national requirements and international norms concerning confidentiality.

\section{Samples}

Thirty-eight breast milk-feeding women donated about $100 \mathrm{~mL}$ (each women) and collected from five hospitals located in Central and Eastern regions of Saudi Arabia (including 2 hospitals in Riyadh, one hospital in each of AL-Kharj, Dammam and Al-Jubail). The participating mothers in this study were from 26 to 37 years old (mean 31 years, median 31years) Milk samples were collected by trained nurses after filling the donor's data sheet according to the WHO/ UNEP-Coordinated Survey Questionnaire for Human Milk donors for POPs analysis. ${ }^{10}$ Samples were taken by breast sterilized glass pump (new pump/women) and transferred directly to clean dark glass jars with a Teflon cap, then transported under cooling to the Chromatographic Analysis Laboratory, Soil science Dept., College of Food and Agricultural Sciences. Samples were prepared and extracted in same day (Riyadh and AL-Kharj) or stored under $-20^{\circ} \mathrm{C}$ until the sample preparation, extraction and analysis of PCBs. All the sample donors were healthy women and the breast milk was collected within the period of 2-8weeks from their parturition.

\section{Preparation}

Each breast milk sample was taken after thawing, homogenized by shaking for 5 minutes directly before splitting. Each sample was labelled with a unique identification code, $25 \mathrm{ml}$ from each sample was taken and diluted 1:1 with phosphate buffered saline and then centrifuged at 2,500 rpm for $10 \mathrm{~min}$ under cooling centrifuge to isolate the fats and remove cells (breast epithelial cells, immune system cells, and foam cells) from the breast milk. Fat fractions were transferred with $2 / 3$ of its skim milk to freeze dried or dark glass vials previously washed with a chromic mixture and were extracted.

\section{Extraction}

Accelerated Solvent Extraction ASE 350 from Dionex Inc., (Sunnyvale, CA, USA) technology was used as extraction techniques and has been shown to produce good recoveries, ratability and sensitivity for PCBs and other POPs in breast milk samples and is approved for use in U.S. EPA SW-846 Method 3545 for the extraction of PCBs, OCPs, BNAs, OPPs, herbicides, and dioxins and furans. Fat fractions of $25 \mathrm{ml}$ of breast milk samples were transferred with $2 / 3$ of its skim milk to freeze dryer for over $15 \mathrm{~h}$ and dry matter was determined gravimetrically. After drying, quantitatively (fat part) transferred to the stainless steel (ASE) cell ( 34 and $11 \mathrm{ml}$ size) was pre-cleaned by rinsing with mixture of dichloromethane: Methanol $1: 1$, and mixed with diatomaceous earth and a $1 \mathrm{~g}$ of anhydrous sodium sulfate. Samples were extracted under the following ASE conditions: $125^{\circ} \mathrm{C}, 1500 \mathrm{psi}$, heatup time: $5 \mathrm{~min}$, static time: $3 \mathrm{~min}$, extracted cycle was 2 times with $60 \%$ flush volume of a mixture of acetone, dichloromethane and methanol, 3:2:1, v:v:v. Total extraction time was $18 \mathrm{~min}$ and total solvent use was $90 \mathrm{ml}$ per sample. The extract collected in the ASE was evaporated using Rotary Evaporators (Buchi, Switzerland), and adjusted to $1 \mathrm{~mL}$ Methanol and transferred to umber GC vials. Same ASE 350 procedures was applying for breast, spiked internal standards of $13 \mathrm{C} 12$ labelled for 4 PCBs congeners $(28,101,153,80$,and209) were used and blank samples. Concentrated extract was applying for the analysis.

\section{Analysis}

PCBs analysis was performed using Thermos Scientific ${ }^{\text {TM }}$ TSQ $8000^{\mathrm{TM}}$ triple quadrupole GC-MS/MS system equipped with the Thermo Scientific ${ }^{\text {TM }}$ TRACETM 1310 GC Selected reaction monitoring (SRM) 11,000transition/run. The mode was Electronic Ionization (EI) $70 \mathrm{eV}$, and transition mode for SRM are EI ion source, polarity positive, electron lens voltage $15 \mathrm{v}$, electron energy $70 \mathrm{eV}$, emission current $50 \mu \mathrm{A}$, MS transfer line $280^{\circ} \mathrm{C}$, Ion source temperature $250^{\circ} \mathrm{C}$, and Q1, Q3 frequency 1091.0, 1098.4 respectively. All measurements have been carried out. Injection mode was spiltless, Splitless Time 1.0 min, TriPlus RSH Autosampler Injection volume $1 \mu \mathrm{L}$. GC Column TR $^{\text {TM }} 5 \mathrm{MS}, 30 \mathrm{~m} \times 0.25 \mathrm{~mm} \times 0.25 \mu \mathrm{m}$, Capillary column TR-5MS $30 \mathrm{mx} 0.25 \mathrm{mmIDx} 0.25 \mu \mathrm{m}$ for PAHs and PCBs Analysis.

Carrier gas He $99.999 \%$, Flow $1.2 \mathrm{~mL} / \mathrm{min}$, constant flow with gas saver unit, Temperature program $100^{\circ} \mathrm{C}, 1 \mathrm{~min} ; 10^{\circ} \mathrm{C} / \mathrm{min}$ to $180^{\circ} \mathrm{C}, 4$ min and $10^{\circ} \mathrm{C} / \mathrm{min}$ to $270^{\circ} \mathrm{C}, 2 \mathrm{~min}$, Transfer line temperature $280^{\circ} \mathrm{C}$. Total analysis time 46.4 mins, for 33 PCBs congeners. Recovery of analytical method was investigated with 10 spiked milk samples by the 18 congeners at level $10,5,2.5,1,0.5,0.25,0.1,0.05,0.025$ and $0.01 \mathrm{ng} \mathrm{g}^{-1}$ lipid weight. Recovery of completely analytical method (Table 2) and 10 spiked lipid extracts with three replicates were submitted to the same procedure, described above. Precision of analytical method (repeatability) was also determined, expressed as relative standard deviation, from analyses of 10 spiked samples. Repeatability of GC-MS was estimated by 3 times injection of spiked lipid extract with three replicates (Table 2).

\section{QAQC Strategies}

Quality control samples were prepared for each batch of 10 samples as follows: duplicate samples; a blank; a matrix spike sample fortified with the 18 congeners (Table 2) at a concentration of 10,5 , $2.5,1,0.5,0.25,0.1,0.05,0.025$ and $0.01 \mathrm{ng} \mathrm{g}^{-1}$ lipid weight. Certified Reference material CRM was prepared for this purpose and processed with each batch of samples. The method limit of detection (LOD) and Limit of Quantification (LOQ), was determined for each compound in the groups State the LOD and LOQ for each compound. Calibration curves were constructed for each PCBs compounds using a series of 10 levels $(0.01-10 \mathrm{ng} / \mathrm{g})$ of concentrations of each compound that cover the dynamic range in which the targeted compounds are expected to be present. Quality assurance was maintain throughout the course of the study using standard quality assurance procedures and documentation. For external assessment Quality control/Quality assurance, some random analyzed samples sent to reference accredited 
lab with the high resolution Gas Chromatography/Mass Spectrometry (HRGC/HRMS).

\section{Statistical analysis}

Statistical analysis applied to calculate minimum, maximum, mean and standard deviation. All the data subjected for statistical analysis of variance (ANOVA, SPSS, I. (2013). IBM SPSS statistics 22. New York: IBM Corp.) to determine the significance of the categorical factors on different PCBs levels. Any differences caused by variability among the sample groups will be accounted using the SPSS (Statistical Package for the Social Sciences) software (V11 version).

\section{Research ethics}

The human milk samples collected and the questionnaires completed was used specifically after getting the Ethical Committee approval of each targeted hospitals in central and eastern of Saudi Arabia, for the purposes of this research, and not be employed for other purposes. All provided data in this research project by mothers that may permit their personal identification, and maintained the confidentiality and not be disclosure.

\section{Results and discussions}

\section{Demographic features of the participants}

There were 38 participants from the Central and Eastern regions of Saudi Arabia from which 12 from Dammam, 6 from Al-Jubail, 15 from Riyadh and 5 from AL-Kharj. The ages of the participants ranged from 26 to 36 years (mean \pm SD, $31 \pm 2.65$ years). The concentrations of some congeners in the human milk samples were $<$ LOD (Table 1) and treated these samples as not detected when calculated the total amount of PCBs.

\section{Sum of PCBs}

The concentrations of 18 PCB congeners determined in 38 individual samples of human milk are presented in Table 2. Sum PCBs refers to the sum of the mean concentrations of all the congeners listed in Table 2. PCB-81 and PCB-153, the most dominating PCB congeners, which might therefore be used as an indicator for sum PCBs. The obtained results in these surveys seem to be in the middle of the range of data published from other studies and recent published by $\mathrm{UNEP}^{11}$ and $^{12-15} \mathrm{PCB}-81$ congener was the dominant non-ortho congener (Table 2) (Figure 1). This finding is different from what has been reported in a Swedish and a Canadian human milk survey which showed PCB-126 as the dominating non-ortho congener. The sum of non-ortho PCBs was higher in our study as compared to the Swedish. ${ }^{16}$ The level of PCB-126 and PCB-169 was higher by $60 \%$ and $75 \%$, respectively, in the Norwegian human milk samples as compared to the Swedish human milk. There was a significant differentiation with respect to the location of industrial estates in the area of residence; there were no statistical differences between the age, occupation, and the congeners studied.

Different studies done by the WHO to measure the PCBs congeners in human milk in 1987-1988, 1992-1993 and 2001-2003 in several countries, ${ }^{17-19}$ the levels of contaminants in human milk were lower in the Southern hemisphere (Fiji, Brazil, Philippines, Australia, New Zealand). In the Eastern Europe (Bulgaria, Croatia, Hungary), Ireland and USA, and higher in Western Europe (Italy, Spain, Germany, Luxembourg, Belgium, Netherlands) and in Ukraine, where very high. In addition, Concentrations of PCBs were very high in India (21 and 16.3) but low elsewhere (5.6 and 3.6 in Cambodia, 6.0 and 7.5 in Vietnam, 7.5 and 4.4 in Philippines. ${ }^{20}$ In Chania, the mean $\Sigma \mathrm{PCB}$ concentration in breast milk from the urban group $(\mathrm{n}=23)$ was $42774 \pm 27841 \mathrm{pg} \mathrm{g}^{-1}$ lipid, which is significantly (p b0.05) higher than in breast milk from the rural group $(\mathrm{n}=51,26546 \pm 11375 \mathrm{pg} \mathrm{g}-1$ lipid, $\left.{ }^{21}\right)$.

\section{Risk assessment for infants}

Table 3 showed that the calculated an estimated daily intake (EDI) to examine infants exposure to PCBs compounds. The calculation is based on assumption that a $5 \mathrm{~kg}$ infant ingests $700 \mathrm{~g}$ milk per day ${ }^{22}$ and the following equation was used:

$$
\mathrm{EDI}=\frac{\mathrm{C}_{\mathrm{mil}} \mathrm{k} \times \mathrm{C}_{1} \mathrm{ipid} \times 700 \mathrm{~g}}{5}
$$

Where EDI is the daily intake ( $\mu \mathrm{g} / \mathrm{kg}$ body wt./day), $\mathbf{C m i l k}$ is the concentration of PCBs in the milk $(\mu \mathrm{g} / \mathrm{kg}$ lipid wt.) and Clipid is the lipid content in milk (\%). The results are given in Table 3 as ranges and medians of individual intakes. Calculated EDI values are one to two orders of magnitude lower than TDI, except for PCBs (the highest individual EDI is two times lower than corresponding TDI). Based on these results we can say with certainty that infants consuming human milk analyzed in this study are not at risk of adverse effects caused by organochlorine compounds (Table 3 ).

Table I PCBs Congeners structure, TEF, LOD and recovery percentage of tested mother milk samples

\begin{tabular}{|c|c|c|c|c|c|c|}
\hline \multirow[t]{2}{*}{ No } & \multirow[t]{2}{*}{ IUPAC \# } & \multirow[t]{2}{*}{ CAS \# } & \multirow[t]{2}{*}{ Structure } & \multirow{2}{*}{$\begin{array}{l}\text { TEF } \\
\text { WHO } 2005\end{array}$} & \multirow{2}{*}{$\begin{array}{l}\text { LOD } \\
(\mu g / k g)\end{array}$} & \multirow{2}{*}{$\begin{array}{l}\text { Recovery \% } \\
\pm \text { SD }\end{array}$} \\
\hline & & & & & & \\
\hline 1 & 28 & $7012-37-5$ & 2,4,4'-Trichlorobiphenyl & NA & 0.005 & $100.77 \pm 2.08$ \\
\hline 2 & 52 & $35693-99-3$ & 2,2,5,5-Tetrachlorobiphenyl & NA & 0.004 & $97.89 \pm 3.22$ \\
\hline 3 & 77 & $32598-13-3$ & 3,3',4,4'-Tetrachlorobiphenyl & 0.0001 & 0.005 & $98.84 \pm 2.66$ \\
\hline 4 & 81 & $70362-50-4$ & 3,4,4',5-Tetrachlorobiphenyl & 0.0003 & 0.004 & $99.39 \pm 4.33$ \\
\hline 5 & 101 & $37680-73-2$ & 2,2,4,5,5-Pentachlorobiphenyl & NA & 0.005 & $98.43 \pm 2.51$ \\
\hline 6 & 105 & $32598-14-4$ & 2,3,3',4,4'- Pentachlorobiphenyls & NA & 0.005 & $98.64 \pm 2.74$ \\
\hline 7 & 114 & $74472-37-0$ & 2,3,4,4',5- Pentachlorobiphenyls & 0.00003 & 0.003 & $101.59 \pm 2.49$ \\
\hline 8 & 118 & $31508-00-6$ & $2,3^{\prime}, 4,4^{\prime}, 5$ - Pentachlorobiphenyls & 0.00003 & 0.004 & $102.09 \pm 2.88$ \\
\hline
\end{tabular}


Table Continued.

\begin{tabular}{|c|c|c|c|c|c|c|}
\hline \multirow[t]{2}{*}{ No } & \multirow[t]{2}{*}{ IUPAC \# } & \multirow[t]{2}{*}{ CAS \# } & \multirow[t]{2}{*}{ Structure } & \multirow{2}{*}{$\begin{array}{l}\text { TEF } \\
\text { WHO } 2005\end{array}$} & \multirow{2}{*}{$\begin{array}{l}\text { LOD } \\
(\mu g / k g)\end{array}$} & \multirow{2}{*}{$\begin{array}{l}\text { Recovery \% } \\
\text { SD }\end{array}$} \\
\hline & & & & & & \\
\hline 9 & 123 & $65510-44-3$ & 2',3,4,4',5- Pentachlorobiphenyls & 0.00003 & 0.005 & $99.61 \pm 2.80$ \\
\hline 10 & 126 & $57465-28-8$ & 3,3',4,4',5-Pentachlorobiphenyl & 0.1 & 0.005 & $102.43 \pm 1.75$ \\
\hline 11 & 138 & $35065-28-2$ & 2,2',3,4,4',5'-Hexachlorobiphenyl & NA & 0.005 & $96.7 I \pm 1.77$ \\
\hline 12 & 153 & $35065-27-1$ & 2,2,4,4,5,5-Hexachlorobiphenyl & NA & 0.005 & $|03.73 \pm 2.6|$ \\
\hline 13 & 156 & $38380-08-4$ & 2,3,3',4,4',5- Hexachlorobiphenyls & 0.00003 & 0.003 & $99.82 \pm 3.04$ \\
\hline 14 & 157 & $69782-90-7$ & 2,3,3',4,4',5'- Hexachlorobiphenyls & 0.00003 & 0.003 & $98.84 \pm 2.41$ \\
\hline 15 & 167 & $52663-72-6$ & 2,3',4,4',5,5'- Hexachlorobiphenyls & 0.00003 & 0.003 & $99.05 \pm 4.18$ \\
\hline 16 & 169 & $32774-16-6$ & 3,3',4,4',5,5'-Hexachlorobiphenyl & 0.03 & 0.003 & $97.43 \pm 1.44$ \\
\hline 17 & 180 & $35065-29-3$ & 2,2,3,4,4,5,5-Heptachlobiphenyl & 0.00001 & 0.005 & $99.52 \pm 3.11$ \\
\hline 18 & 189 & $527 \mid 2-05-7$ & 2,3,3',4,4',5,5'-Heptachlorobiphenyls & 0.00003 & 0.005 & $98.75 \pm 2.55$ \\
\hline
\end{tabular}

Table 2 Statistical parameters for most contributed PCBs congeners $(\mathrm{ng} / \mathrm{kg})$ to $\Sigma \mathrm{PCBs}$ in mother milk

\begin{tabular}{|c|c|c|c|c|c|c|c|c|c|c|c|c|c|c|c|c|c|c|c|}
\hline & & \multicolumn{4}{|c|}{ Non-Ortho PCBs } & \multicolumn{8}{|c|}{ Mono-Ortho PCBs } & \multicolumn{6}{|c|}{ I-PCBs } \\
\hline & & $\begin{array}{c}\text { PCB- } \\
77\end{array}$ & $\begin{array}{c}\text { PCB- } \\
81\end{array}$ & $\begin{array}{c}\text { PCB- } \\
126\end{array}$ & $\begin{array}{c}\text { PCB- } \\
169\end{array}$ & $\begin{array}{c}\text { PCB- } \\
105\end{array}$ & $\begin{array}{c}\text { PCB- } \\
114\end{array}$ & $\begin{array}{c}\text { PCB- } \\
118\end{array}$ & $\begin{array}{c}\text { PCB- } \\
123\end{array}$ & $\begin{array}{c}\text { PCB- } \\
156\end{array}$ & $\begin{array}{c}\text { PCB- } \\
157\end{array}$ & $\begin{array}{c}\text { PCB- } \\
167\end{array}$ & $\begin{array}{c}\text { PCB- } \\
189\end{array}$ & $\begin{array}{c}\text { PCB- } \\
28\end{array}$ & $\begin{array}{c}\text { PCB- } \\
52\end{array}$ & $\begin{array}{c}\text { PCB- } \\
101\end{array}$ & $\begin{array}{c}\text { PCB- } \\
138\end{array}$ & $\begin{array}{c}\text { PCB- } \\
153\end{array}$ & $\begin{array}{r}\text { PCB- } \\
180\end{array}$ \\
\hline \multirow{6}{*}{ Eastern } & $\Sigma$ PCBs & 34.71 & 94.02 & 6.38 & 30.98 & 26.6 & 21.76 & 39.71 & 5.26 & 5.67 & 5.77 & 1.36 & 35.7 & 14.13 & 4.06 & 2.83 & 52.34 & 62.25 & 44.65 \\
\hline & mean & 1.93 & 5.22 & 0.38 & 1.72 & 1.48 & 1.21 & 2.21 & 0.29 & 0.33 & 0.36 & 0.1 & 1.98 & 0.79 & 0.24 & 0.22 & 2.91 & 3.46 & 2.48 \\
\hline & median & 1.8 & 0.89 & 0.32 & 1.38 & 1.35 & 1.2 & 2.03 & 0.3 & 0.31 & 0.32 & 0.08 & 1.86 & 0.81 & 0.19 & 0.07 & 2.57 & 3.46 & 2.31 \\
\hline & Max & 3.31 & 77 & 0.78 & 3.27 & 2.31 & 2.82 & 3.88 & 0.73 & 0.77 & 0.78 & 0.34 & 3.31 & 1.55 & 0.48 & 0.72 & 5.31 & 5.12 & 3.51 \\
\hline & Min & 0.94 & 0.35 & 0.18 & 1.04 & 1.01 & 0.14 & 1.25 & 0.07 & 0.13 & 0.18 & 0.04 & 0.94 & 0.26 & 0.12 & 0.04 & 0.69 & 0.92 & 1.58 \\
\hline & SD & 0.77 & 17.92 & 0.18 & 0.64 & 0.43 & 0.77 & 0.75 & 0.15 & 0.17 & 0.16 & 0.08 & 0.79 & 0.36 & 0.12 & 0.24 & 1.25 & 1.15 & 0.59 \\
\hline \multirow{6}{*}{ Central } & $\Sigma$ PCBs & 34.89 & 52.42 & 3.25 & 24.62 & 23.38 & 30.84 & 28.82 & 4.27 & 4.18 & 3.4 & 4.24 & 34.89 & 7.01 & 3.52 & 4.05 & 44.91 & 40.24 & 38.21 \\
\hline & Mean & 1.71 & 2.81 & 0.16 & 1.29 & 1.17 & 1.78 & 1.42 & 0.22 & 0.22 & 0.17 & 0.22 & 1.71 & 0.36 & 0.21 & 0.21 & 2.11 & 2.02 & 1.78 \\
\hline & median & 1.53 & 0.65 & 0.09 & 0.99 & 1.05 & 1.33 & 1.26 & 0.08 & 0.08 & 0.08 & 0.16 & 1.53 & 0.32 & 0.14 & 0.09 & 2.03 & 1.83 & 1.66 \\
\hline & Max & 4.2 & 37 & 0.58 & 3.25 & 2.22 & 3.27 & 2.44 & 0.78 & 0.77 & 0.78 & 0.7 & 4.2 & 0.78 & 0.55 & 0.79 & 4.42 & 3.52 & 3.43 \\
\hline & Min & 0.98 & 0.24 & 0.03 & 0.57 & 0.52 & 1.04 & 0.88 & 0.04 & 0.04 & 0.03 & 0.05 & 0.98 & 0.18 & 0.08 & 0.03 & 1.36 & 0.94 & 0.91 \\
\hline & SD & 0.76 & 8.11 & 0.17 & 0.66 & 0.53 & 0.69 & 0.49 & 0.25 & 0.25 & 0.22 & 0.2 & 0.76 & 0.17 & 0.15 & 0.26 & 0.88 & 0.83 & 0.85 \\
\hline
\end{tabular}

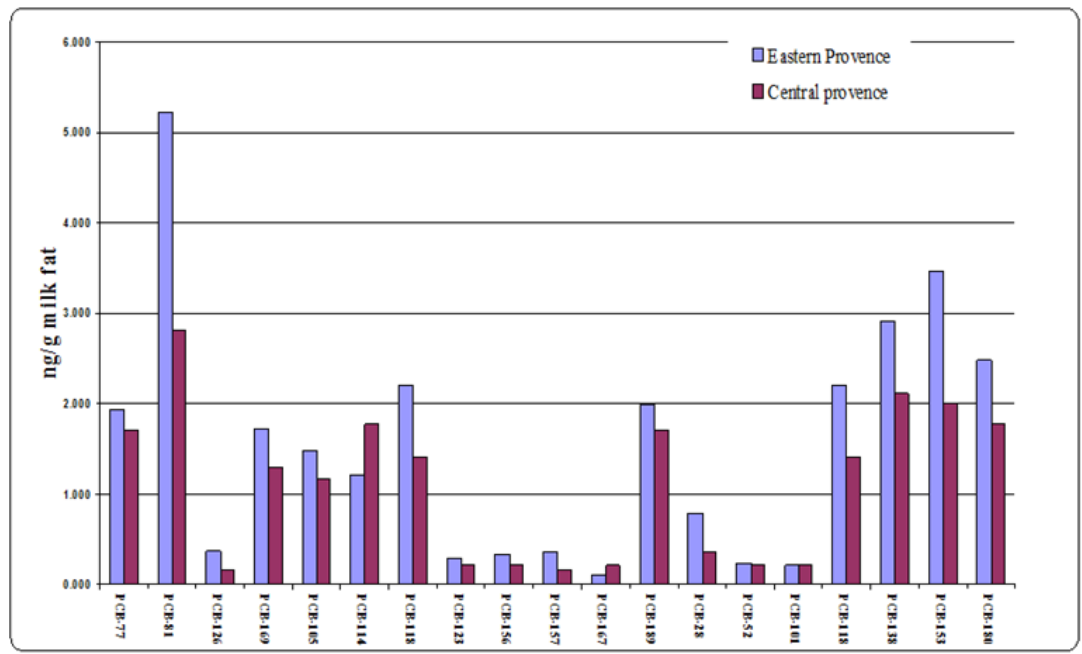

Figure I: Comparison of mean concentrations between the human milk samples collected in Eastern and Central provinces in Saudi Arabia.

Citation: EL-Saeid MH, Sapp JB, Hassanin A. Congener specific determination of polychlorinated biphenyls (PCBs) in human milk. Adv Plants Agric Res. 2017;6(4): 108-II2. DOI: 10.15406/apar.2017.06.00222 
Table 3 Range(median) of estimated daily intake(ng/kg body wt./day)

\begin{tabular}{lll}
\hline Eastern provence & Central provence & EDI \\
\hline $0.298-0.053(0.086)$ & $0.178-0.035(0.065)$ & $1.0 \mu g / \mathrm{kg}$ body $w t . /$ day \\
\hline
\end{tabular}

\section{Conclusions}

The results of this study have provided a baseline level for 18 PCBs congeners in the first study investigating the PCBs levels in mother breast milk in eastern and central of Saudi Arabia. The estimated EDI of breast-fed infants were lower those of some non-exposure areas in central and eastern of Saudi Arabia and that infants consuming human milk analyzed in this study are not at risk of adverse effects caused by tested PCBs, campaign to the exposure levels of many developed countries. The level of PCBs in eastern were higher than central areas may be due to the industrial activates in eastern areas. This will greatly help the Saudi government take steps to control and eliminate these POPs in the future. ${ }^{23}$

\section{Acknowledgements}

This Project was funded by the National Plan for Science, Technology \& Innovation (MAARIFAH), King Abdulaziz City for Science \& Tech. Kingdom of Saudi Arabia, Award and Project No. 12-ENV-2585-2.

\section{Conflict of interest}

The author declares no conflict of interest.

\section{References}

1. Brouwer A, Ahlborg UG, Leeuwen FX, et al. Report of the WHO working group on the assessment of health risks for human infants from exposure to PCDDs, PCDFs and PCBs. Chemosphere. 1998;37(9-12):1627-1643.

2. UNEP. Preparation of an internationally legally binding instrument for implementing international action on certain persistent organic pollutants United Nations Environment Programme UNEP/POPs/Inc 1/6; 1998.

3. Anyasi RO, Atagana HI. Biological remediation of polychlorinated biphenyls (PCB) in the environment by microorganisms and plants. African Journal of Biotechnology. 2011;10(82):18916-18938.

4. Maruyama W, Aoki Y. Estimated cancer risk of dioxins to humans using a bioassay and physiologically based pharmacokinetic model. Toxicology and Applied Pharmacology. 2006;214(2):188-198.

5. Bonefeld-Jorgensen E, Long CM. Does exposure to persistent organic pollutants (POPs) increase the risk of breast cancer? Toxicology Letters Abstracts of the XII International Congress of Toxicology. 2010;196:S52-S53.

6. Garzon AM, Sweeney A, del Junco D, et al. A case-control study of birth defects, cancer and dioxin exposure. Epidemiology. 2002;13:S187-S187.

7. Lawson CC, Schnorr T, Whelan M, et al. Paternal occupational exposure to 2,3,7,8-tetrachlorodibenzo-p-dioxin and birth outcomes of offspring:birth weight, preterm delivery, and birth defects. Environmental Health Perspectives. 2004;112(14):1403-1408.
8. Bursian S, Newsted J, Zwiernik LMJ. Polychlorinated biphenyls, polychlorinated dibenzo-p-dioxins and polychlorinated dibenzofurans. San Diego: Reproductive and Developmental Toxicology In Academic Press; 2011. p. 543-567.

9. Lai T, Liu J, Leon XC, et al. A cohort study of behavioral problems and intelligence in children with high prenatal polychlorinated biphenyl exposure. Archives of General Psychiatry. 2002;59(11):1061-1066.

10. WHO. Fourth WHO-Coordinated Survey of Human Milk for Persistent Organic Pollutants in Cooperation with UNEP. Guidelines for Developing a National Protocol. Geneva: World Health Organization; 2007.

11. UNEP. Results of the global survey on concentrations in human milk of persistent organic pollutants by the United Nations Environment; 2013.

12. Zhao GF, Wang ZJ, Zhou H, et al. Burdens of PBBs, PBDEs, and PCBs in tissues of the cancer patients in the e-waste disassembly sites in Zhejiang, China. Science of the Total Environment. 2009;407(17):4831-4837.

13. Černá M, Krsková A, Čejchanová M, et al. Human biomonitoring in the Czech republic: an overview. International Journal of Hygiene and Environmental Health. 2012;215(2):109-119.

14. Perharic L, Vracko P. Development of national human biomonitoring programme in Slovenia. International Journal of Hygiene and Environmental Health. 2012;215(2):180-184.

15. Klinčić D, Romanić S, Sarić HM, et al. Polychlorinated biphenyls and organochlorine pesticides in human milk samples from two regions in Croatia. Environmental Toxicology and Pharmacology. 2014;37:543552.

16. Lignell S, Aune M, Darnerud PO, et al. Persistent organochlorine and organobromine compounds in mother's milk from Sweden 19962006: Compound-specific temporal trends. Environmental Research. 2009;109(6):760-767.

17. WHO Regional Office for Europe. Levels of PCBs, PCDDs, and PCDFs in Breast Milk. Environmental Health Series 34. Copenhagen Denmark; 1989.

18. WHO Regional Office for Europe. Levels of PCBs, PCDDs and PCDFs in Human Milk:Second Round of WHO-coordinated Exposure Study. Environmental Health in Europe 3. Copenhagen Denmark; 1996.

19. Van Leeuwen FXR, Malisch R. Results of the third round of the WHO coordinated exposure study on the level of PCBs, PCDDs, and PCFDs in human milk. Organochalogen Compd. 2002;56:311-316.

20. Ulaszewska MM, Ettore Zuccato, Enrico Davoli. PCDD/Fs and dioxin-like PCBs in human milk and estimation of infants' daily intake:A review. Chemosphere. 2011;83(6):774-782.

21. Shen H, Gangqiang Ding, Yongning Wu, et al. Polychlorinated dibenzo-p-dioxins/furans (PCDD/Fs), polychlorinated biphenyls (PCBs), and polybrominated diphenyl ethers (PBDEs) in breast milk from Zhejiang, China. Environ Int. 2012;42:84-90.

22. Van Oostdam J, Gilman A, Dewailly E, et al. Human health implications of environmental contaminants in Arctic Canada:a review. Science of the Total Environment. 1999;230(1-3):1-82.

23. Programme and the World Health Organization. Conference of the Parties to the Stockholm Convention on Persistent Organic Pollutants Sixth meeting Geneva; 2013. 